\title{
O Ensino da Fisiatria nos Cursos de Graduação das Escolas de Medicina*
}

Orlando M. Fontes

\section{Introdução - A Demanda de Atendimento Fisiátrico}

A demanda de atendimento fisiátrico à população é grande e contrasta com a carência numérica de médicos especializados em Fisiatria.

Os reclamos pela prestação da assistência fisiátrica crescem a olhos vistos, enquanto os cursos de graduação médica ignoram o problema durante lustros consecutivos.

Tanto é assim que, apenas cinco escolas de medicina do país incluem o ensino da Fisiatria em seus currículos.

Isto é o que acontece, apesar de $10 \%$ da população carecerem de assistência de reabilitação.

Há legiões de asmáticos, bronquíticos, enfisematosos, hansenianos, reumáticos, miopatas, encefalopatas, mielopatas, diabéticos, traumatizados... carecendo de tratamento fisiátrico.

\section{Conceito de Fisiatria}

Fisiatria, medicina física, medicina física e reabilitação, medicina de reabilitação é o mesmo que "physiatry, physical medicine and rehabilitation, rehabilitation medicine" nos países anglo-saxônicos.

Trata-se de um ramo da medicina que utiliza os recursos comuns da propedêutica e terapêutica médicas e especificamente, os agentes físicos, as atividades ocupacionais, órteses, próteses, a tecnologia... com a finalidade de curar ou atenuar as deficiências físicas.

...e ainda confere grande importância ao abrèviamento de internação hospitalar, ao período de convalescença, ao restabelecimento das funções, da capacidade laborativa, da independência física e econômica... à reintegração social e à revalorização da pessoa humana.

Dentro deste escopo opera a Fisiatria, a terceira fase da medicina e procura atingir as metas individuais de cada paciente.

* Resumo do documento original elaborado pelo Acadêmico Prof. Dr. Orlando M. Fontes, Coordenador do Simpósio, e apresentado no Rio de Janeiro em outubro de 1994. 


\section{Âmbito da Fisiatria}

A fisiatria distingue-se de outras especialidades pelo fato de atender pacientes com sintomas, disfunções, lesões e enfermidades de diversos órgãos, aparelhos ou sistemas ao contrário de outros especialistas que atendem apenas e especialmente a um tipo de doente. Exemplo, o cardiologista atende apenas a cardiopatas.

Tal delimitação de área clínica não ocorre em fisiatria, pois o fisiatra atende pacientes portadores de lesões, disfunções ou enfermidades respiratórias, dermatológicas, cárdio-vasculares, ortopédicas, neurológicas, reumáticas etc.

As legiões de pessoas que atingem a terceira idade constituem uma grande parcela da população que não pode prescindir da assistência fisiátrica.

\section{O Ensino da Fisiatria}

Reconhecendo-se que a procura de tratamento fisiátrico é ingente e tende a aumentar, e considerando-se que a fisiatria profilática é muito pouco praticada por causa do exíguo conhecimento desta especialidade no meio médico, conclui-se que a ausência do ensino de fisiatria nos cursos de graduação representa um dos fatores mais importantes da escassa assistência de reabilitação prestada no país.

Este enfoque induziu a Academia de Medicina de Reabilitação e o Inst. de Pós-Graduação Médica Carlos Chagas a promoverem um simpósio sobre o ensino da fisiatria nos cursos médicos.

Com este objetivo iniciamos uma pesquisa junto às escolas de medicina de nosso país e com o apoio do Cônsul Geral dos Estados Unidos no Rio de Janeiro, Sr. David Zweifell, dirigimo-nos à American Academy of Physical Medicine and Rehabilitation com o fito de obter informações a respeito do assunto nos Estados Unidos.

Os pronunciamentos dos participantes do simpósio convergiram em reconhecer a necessidade de incluir a fisiatria no currículo de graduação das nossas escolas de medicina.

\section{Proposição da ABMR e do IPGMCC}

A Academia Brasileira de Medicina de Reabilitação e o Instituto de Pós-Graduação Médica Carlos Chagas reconhecem a necessidade de inclusão da fisiatria no currículo de graduação das escolas de medicina como disciplina obrigatória e independente;

O ensino da fisiatria em todos os graus, deverá ser ensinado por médicos fisiatras com título de especialistas ou título de magistério universitário nesta área.

O ensino da fisiatria terá por finalidade difundir os conhecimentos básicos desta especialidade médica para todos os graduandos em medicina.

Em todas as faculdades de medicina deverá ser instituída a residência médica em fisiatria... sob a direção técnica do médico fisiatra titulado ou de médico portador do título de Mestre ou Doutor em fisiatria.

\section{O Ensino da Fisiatria nos Estados Unidos}

Constam da carta do Dr. Ronald Enricha, diretor executivo da American Academy of Physical Medicine and Rehabilitation, respondendo às nossas indagações, as seguintes informações:

Existem 125 escolas de medicina nos Estados Unidos;

Em 76 destas escolas existe residência médica em fisiatria;

A American Academy recomenda que a fisiatria seja ensinada em todas as escolas médicas;

A American Academy recomenda que fisiatras aproveitados como mentores clínicos quando as escolas não dispuserem de professores;

...sustenta que o ensino da fisiatria a médicos ou estudantes de medicina seja feito por médicos fisiatras.

Embora o simpósio esteja encerrado, a Academia de Medicina de Reabilitação e o Inst. de Pós-Grad. Médica Carlos Chagas prosseguem nos estudos e demarches que visam aprimorar o ensino médico em nosso país. 